\title{
Prolactin gene expression in primary central nervous system tumors
}

\author{
Graziella Alebrant Mendes ${ }^{1 *}$, Júlia Fernanda Semmelmann Pereira-Lima ${ }^{1,2}$, Maria Beatriz Kohek, Geraldine Trott ${ }^{3}$, \\ Marlise Di Domenico ${ }^{3}$, Nelson Pires Ferreira ${ }^{2}$ and Miriam da Costa Oliveira ${ }^{1,2}$
}

\begin{abstract}
Background: Prolactin (PRL) is a hormone synthesized in both the pituitary gland and extrapituitary sites. It has been associated with the occurrence of neoplasms and, more recently, with central nervous system (CNS) neoplasms. The aim of this study was to evaluate prolactin expression in primary central nervous system tumors through quantitative real-time PCR and immunohistochemistry $(\mathrm{IH})$.

Results: Patient mean age was 49.1 years (SD 15.43), and females accounted for $70 \%$ of the sample. The most frequent subtype of histological tumor was meningioma (61.5\%), followed by glioblastoma (22.9\%). Twenty cases (28.6\%) showed prolactin expression by immunohistochemistry, most of them females (18 cases, 90\%). Quantitative real-time PCR did not show any prolactin expression.
\end{abstract}

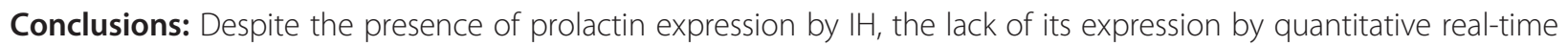
$P C R$ indicates that its presence in primary tumors in CNS is not a reflex of local production.

Keywords: Prolactin, CNS tumors, immunohistochemistry, quantitative real-time PCR, gene expression

\section{Background}

PRL was initially associated with mammary development and lactation. However, more than 300 biological functions have been attributed to this hormone [1]. The human PRL gene is located on chromosome 6 and its expression is not limited to the pituitary gland, occurring also in such extrapituitary sites as endometrium, decidua, myometrium, T lymphocytes, leukocytes, brain, prostate, skin and adipose tissue [2,3]. The gene transcription is further regulated by two independent promoters: a proximal pituitary PRL promoter and a distal extrapituitary PRL promoter [4].

Recent studies have suggested an association of PRL with tumor proliferation, evidencing the hormone as an antiapoptotic or mitogenic factor [1]. Studies showed that PRL extends the lobular-alveolar cells survival on the lactating mammary gland, inhibiting apoptosis and stimulating the proliferation of many cell lines of breast cancer [5]. In vivo studies showed that high levels of PRL accelerated the emergence of spontaneous mammary tumors [6] and

\footnotetext{
*Correspondence: grazi_mendes@hotmail.com

${ }^{1}$ Postgraduate Program in Pathology, Universidade Federal de Ciências da Saúde de Porto Alegre (UFCSPA), Porto Alegre, Brazil

Full list of author information is available at the end of the article
}

could act as an anti-cytotoxic factor in breast cancer cells, contributing to drug resistance [7]. PRL is also involved in prostate tumor growth, acting as a survival factor for epithelial cells, and PRL expression was correlated with tumor differentiation degree [8-10]. In addition, hyperprolactinemia was associated with a worse prognosis in patients with colon and rectum cancer [11].

Regarding the CNS, there are studies showing the presence of hyperprolactinemia, intracellular PRL and PRL receptor (PRL-R) in different types of CNS tumors $[12,13]$, and intracellular PRL and serum PRL were associated with a tendency of increased vascular density and significant increase of cell proliferation markers Ki-67 and $\mathrm{Mcm}-2$, suggesting that PRL may play a role in the development of these tumors [14].

The purpose of this study was to assess PRL expression in primary CNS tumors by real-time PCR and to correlate these findings with immunohistochemical hormone detection, contributing to a better understanding of the interrelationship between PRL and CNS tumors.

\section{Results}

The study included 70 patients: 49 (70\%) females and 21 (30\%) males. Their mean age was 49.1 years (SD 15.43).

\section{Biomed Central}


The mean age of the group with positive IH (54.90 years) was statistically significantly different $(p=0.046)$ from that of the group with negative IH (46.78 years).

As for pathological diagnosis, the most frequent histological subtype was meningioma (43 cases, $61.5 \%$ ), followed by glioblastoma (16 cases, 22.9\%), astrocytoma (5 cases, 7.2\%) oligoastrocytoma and anaplastic oligodendroglioma (2 cases each, 2.8\%), anaplastic ependymoma (1 case, $1.4 \%$ ), and glioma (1 case, $1.4 \%$ ). Regarding tumor location, 43 cases (61.5\%) were located in the meninges, 26 cases (37.1\%) were supratentorial, and 1 case (1.4\%) infratentorial.

Regarding IH expression of intracellular PRL, 20 cases were positive, representing $28.6 \%$ of the sample with a predominance of females (18 cases, $90 \%$ ). Of the positive cases, 15 were meningiomas (transitional meningioma, 8 cases, $40 \%$; meningeal meningioma, 5 cases, $25 \%$; psammomatous meningioma, 1 case, $5 \%$; secretory meningioma, 1 case, 5\%), one was oligoastrocytoma (5\%) and 4 were glioblastomas (20\%) (Table 1). See Figure 1 and 2. Statistical significance was obtained by relating gender (18 females versus 2 males) to IH PRL positivity ( $\mathrm{p}=$ 0.043). There was no statistically significant relationship of IH PRL positivity with age ( $<40$ and $\geq 40$ years), pathological diagnosis, and tumor location (Table 2).
Quantitative real-time PCR failed to show any PRL expression in both normal CNS tissue and CNS tumor samples.

\section{Discussion}

The current series is characterized by primary CNS tumor-bearing patients whose ages were similar to those of patients in other studies $[15,16]$. Meningiomas prevailed in association with female predominance [17]. Regarding location, most meningiomas in our sample occurred at different locations as compared to most tumors described in the literature [18].

In our study, $28.6 \%$ of the sample presented positive IH to PRL. Unlike Abech and colleagues' findings [14], PRL was positive in older patients in our series. In 1999, positive IH for PRL was described in a patient with gangliocytoma [19].

Hyperprolactinemia and presence of intracellular PRL and PRL-R have been detected by immunohistochemistry in different types of CNS tumors. Cicarelli and colleagues [12] found hyperprolactinemia and presence of PRL-R in $27.2 \%$ and $45.4 \%$ of meningiomas and $61.5 \%$ and $69.2 \%$ of schwannomas, without correlation of hyperprolactinemia with PRL-R. Leães and colleagues [13] identified hyperprolactinemia in $30.5 \%$, presence of

Table 1 Sex, age, histological diagnosis, location and grade of primary CNS tumors in patients with positive immunohistochemistry for PRL

\begin{tabular}{|c|c|c|c|c|c|}
\hline Case & Sex & Age (years) & Histological diagnosis & Location & Grade \\
\hline 1 & $\mathrm{~F}$ & 74 & Transitional meningioma & Meninge & 1 \\
\hline 2 & $\mathrm{~F}$ & 51 & Glioblastoma & Supratentorial & IV \\
\hline 3 & $\mathrm{~F}$ & 64 & Transitional meningioma & Meninge & 1 \\
\hline 4 & $\mathrm{~F}$ & 53 & Meningeal meningioma & Meninge & 1 \\
\hline 5 & $\mathrm{~F}$ & 69 & Meningeal meningioma & Meninge & 1 \\
\hline 6 & $\mathrm{~F}$ & 49 & Psammomatous meningioma & Meninge & I \\
\hline 7 & $\mathrm{~F}$ & 60 & Transitional meningioma & Meninge & 1 \\
\hline 8 & $\mathrm{~F}$ & 84 & Glioblastoma & Supratentorial & IV \\
\hline 9 & $\mathrm{~F}$ & 57 & Transitional meningioma & Meninge & 1 \\
\hline 10 & $\mathrm{~F}$ & 55 & Meningeal meningioma & Meninge & 1 \\
\hline 11 & $\mathrm{~F}$ & 52 & Meningeal meningioma & Meninge & 1 \\
\hline 12 & $\mathrm{~F}$ & 37 & Glioblastoma & Supratentorial & IV \\
\hline 13 & $\mathrm{~F}$ & 47 & Secretory meningioma & Meninge & 1 \\
\hline 14 & $\mathrm{~F}$ & 34 & Transitional meningioma & Meninge & 1 \\
\hline 15 & $\mathrm{~F}$ & 59 & Meningeal meningioma & Meninge & 1 \\
\hline 16 & $\mathrm{~F}$ & 63 & Glioblastoma & Supratentorial & IV \\
\hline 17 & $\mathrm{~F}$ & 37 & Transitional meningioma & Meninge & 1 \\
\hline 18 & M & 62 & Transitional meningioma & Meninge & $\|$ \\
\hline 19 & $M$ & 34 & Oligoastrocytoma & Supratentorial & $\|$ \\
\hline 20 & $\mathrm{~F}$ & 57 & Transitional meningioma & Meninge & I \\
\hline
\end{tabular}




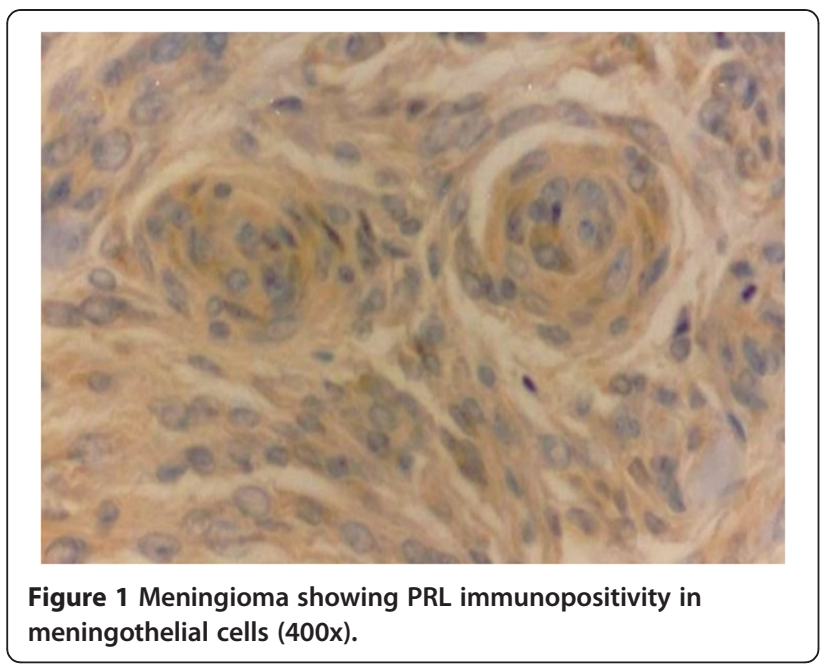

intracellular PRL in $21.9 \%$ and PRL-R in $39 \%$ of 82 cases, with positive correlation of serum PRL with presence of intracellular PRL. A recent study by Abech and colleagues [14] revealed presence of intracellular PRL in $45.6 \%$ of neuroepithelial tumors and meninges and elevated serum PRL in $33.9 \%$ of the cases. Therefore, our findings of positive intracellular PRL are similar to the those of the literature. The meaning of intracellular presence of PRL may vary according to the malignant potentials of the tumors, and there is no data in the current literature on the possible causes for the presence of positive PRL immunohistochemistry in different types of CNS tumors. However, in gliomas of different grades, Scott and colleagues [20] found a significant increase in the expression of Ki-67, Mcm-2 and cyclin A and B1 as tumor grade increased, and it is speculated that PRL, like the above-mentioned proteins, may be related to more aggressive tumors [1]. Ducret and colleagues [21] demonstrated increased intracellular calcium in glioblastoma cells induced by the presence of PRL, increased thymidine incorporation, cell growth and half-life. Regarding

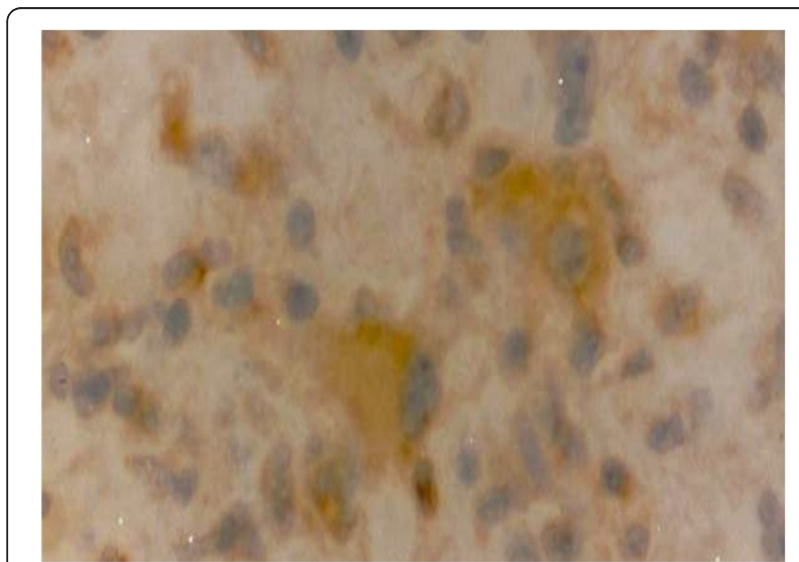

Figure 2 Glioblastoma with PRL immunopositivity (400x).
Table 2 Rates of positivity for PRL by immunohistochemistry

\begin{tabular}{|c|c|c|c|c|}
\hline \multirow[b]{2}{*}{ Variable } & \multirow[b]{2}{*}{$n$} & \multicolumn{2}{|c|}{ PRL IH (+) } & \multirow[b]{2}{*}{$p$} \\
\hline & & $n^{\circ}$ & $\%$ & \\
\hline Age, years & & & & $0.386[1]$ \\
\hline$<40$ & 21 & 4 & 19.0 & \\
\hline$\geq 40$ & 49 & 16 & 32.7 & \\
\hline Sex & & & & $0.043[1]$ \\
\hline males & 21 & 2 & 9.5 & \\
\hline females & 49 & 18 & 36.7 & \\
\hline Histological type & & & & $0.461[2]$ \\
\hline Meningioma & 43 & 15 & 34.9 & \\
\hline Glioblastoma & 16 & 4 & 25.0 & \\
\hline Astrocytoma & 5 & 0 & 0.0 & \\
\hline Others & 6 & 1 & 16.7 & \\
\hline Location & & & & $0.356[2]$ \\
\hline Meninges & 43 & 15 & 34.9 & \\
\hline Supratentorial & 26 & 5 & 19.2 & \\
\hline Infratentorial & 1 & 0 & 0.0 & \\
\hline
\end{tabular}

PRL: prolactin; IH: immunohistochemistry; [1]: Chi-Square Test (Yates); [2]: Fisher's exact test; no: number of cases.

meningiomas, Jimenez-Hakim and colleagues [22] demonstrated that PRL concentrations stimulated the growth of meningiomas significantly.

A single report utilizing conventional PCR detected PRL mRNA expression in the human hypothalamus, pituitary and cerebellum [23]. In studies with rats, PRL mRNA was detected in various degrees in the hypothalamus, cerebellum, caudate, brain stem, amygdala, thalamus, hippocampus and cortex $[24,25]$. In this study, no expression of PRL was identified in the pool of 9 samples of CNS peritumoral tissue (gray and white matter and meningothelial tissue) through quantitative realtime PCR. Real-time PCR is the most powerful tool for quantitative nucleic acids analysis. It is widely considered as the gold standard for nucleic acid quantification and has become the method of choice for the detection of mRNA because of its unparalleled amplification and precision capability [26-29]. Sample of prolactinoma was used as positive control, demonstrating that real-time PCR is able to identify PRL expression. It removes the possibility that the technique was not sensitive enough to detect PRL and to corroborate immunohistochemical findings. In general, polyclonal antibodies have high affinity and wide reactivity, becoming more sensible as compared with monoclonal antibodies because they are more likely to identify multiple epitopes of the target protein. However, their specificity is lower as compared to monoclonal antibodies, being more susceptible to cross-reactivity with other antigens [30]. PCR methods generally have a higher sensitivity and specificity than 
immunohistochemical ones and agreement between results of immunohistochemistry and PCR methods can be low [31-33]. Real time -PCR is the most sensitive method for the detection and quantification of mRNA, especially for low abundance specimens, like RNAs, cells and tissues [27,34]. Real time-PCR assays are 10.000 to 100.000 -fold more sensitive than RNase protection assays, 1000-fold more sensitive than dot blot hybridization, detecting a single copy of a specific transcript and is a method with lower variation, usually between 0 and 5\% for TaqMan probes [27-29,34,35]. The real time -PCR technique, specially with TaqMan probes, is the best option when analyzing gene with low expression level, from limited samples once high sensitivity and accuracy are needed $[27,36]$. There is no data in the current literature about PRL gene expression by quantitative real-time PCR in normal samples of the CNS. To the best of our knowledge, there are no studies analyzing PRL gene expression in different types of CNS tumors either by conventional PCR or by quantitative real-time PCR. Therefore, the absence of PRL expression by quantitative real-time PCR in human samples of different types of CNS tumors, the main finding of this study, is an unprecedented one.

So far, the identification of positive PRL by immunohistochemistry suggested possible extrapituitary hormone production, but immunological methods do not allow to discriminate between locally produced PRL and PRL that is captured by dependent or independent mechanism of the PRL-R. The PRL-R is ubiquitously expressed and its isoforms vary across tissues. The long isoform is highly expressed in the choroid plexus, mammary gland, pancreas, adrenal, kidney and intestine. In the brain, with the exception of the choroid plexus, there is a low expression of PRL-R. PRL-R triggers intracellular signaling pathways, the best known of which being the Jak-Stat. In breast cancer cells, PRL activates Jak2, stimulates phosphorylation of Stat1, Stat 3 and Stat 5 and induces cell proliferation $[37,38]$. In breast cancer cells and Nb2 cells, PRL stimulates ERK1/2 phosphorylation in the mitogen-activated protein (MAP) kinase pathway, which appears to mediate the effects of PRL on cell proliferation $[39,40]$. The PRL-R facilitates the action of members of the Src kinase family, activating kinase B protein and the phosphatidylinositol 3-kinase (PI3 kinase) pathway [41]. The interconnection between the different signaling pathways of PRL can increase the proliferation, survival, cell migration and invasion of breast cancer [42] and is responsible for mediating antiapoptotic and proliferative effects of PRL [43]. The absence of PRL detection by quantitative real-time PCR does not favor the hypothesis of local production because, unlike $\mathrm{IH}$, it is a method that analyses the mRNA of protein in order to identify local production of PRL.
In a study by Abech and colleagues [14], 45.6\% of cases presented positive IH to PRL and $30.6 \%$ of cases presented hyperprolactinemia. In addition, in a study carried out by Leães and colleagues [13], of the total number of patients with positive IH to intracellular PRL, $27.8 \%$ presented hyperprolactinemia, $38.9 \%$ were positive for PRL-R, and $44.4 \%$ had neither of the two variables. Although the available data do not allow us to define the origin of positive IH PRL in primary tumors of the CNS, they strongly suggest that it does not reflect local production. It is postulated that the presence of PRL in CNS is due to the transport of pituitary PRL from the blood by the choroid plexus, with subsequent distribution via cerebrospinal fluid and taking up by neurons and glial cells to exert modulatory functions. It is presumed that the PRL receptor or binding protein in the choroid plexus functions as a transporter, enabling circulating PRL to gain access to various brain regions $[2,44,45]$.

\section{Conclusions}

Despite the presence of prolactin expression by immunohistochemistry, the lack of its expression by quantitative real-time PCR indicates that its presence in primary tumors in central nervous system is not a reflex of local production. Thus, further studies are needed regarding the origin of this PRL identified with the immunohistochemistry technique and its true role in the pathogenesis of CNS tumors.

\section{Materials and methods}

Design: Cross-sectional observational study.

\section{Subjects}

Patients with primary diagnosis of CNS tumor who underwent neurosurgery at Hospital São José, Complexo Hospitalar Santa Casa of Porto Alegre, Brazil, from February 2007 to July 2010 were included in this study. Informed consent was obtained from all subjects before participation. Medical records were reviewed to collect data concerning sex, age, tumor location, and anatomopathological diagnosis. The anatomopathological findings were reviewed by a second pathologist.

The study was conducted in a statistically estimated sample of 70 patients. The research project was approved by the Ethics Committee of the institution $(263 / 09)$.

\section{Immunohistochemistry}

Samples of tumoral tissue were fixed with $10 \%$ buffered formalin and embedded in paraffin. Serial $4 \mu \mathrm{m}$ sections were stained with hematoxylin and eosin and subjected to IH. Polyclonal antihuman antibody (Dako, Carpinteria, CA, code A0569-1, dilution 1:1000) and Advance ${ }^{\mathrm{TM}}$ HRT 
(Dako, Carpinteria, CA, code K4068, ready-to-use) were used for detection of intracellular PRL. Endogenous peroxidase activity was blocked using two baths of 10 minutes in $5 \%$ hydrogen peroxide $\left(\mathrm{H}_{2} \mathrm{O}_{2}\right) 30 \mathrm{~V}$ in methanol. Unspecific proteins were blocked using 1\% BSA for $30 \mathrm{~min}-$ utes. Incubation with primary antibody was performed overnight at $4^{\circ} \mathrm{C}$. Incubation with secondary antibody and tertiary antibody was performed for 40 minutes at room temperature. The same tissues were used as negative controls, incubated with the same antibodies except the primary one, which was replaced by BSA. The antigenantibody binding was visualized with the DAB chromogen (diaminobenzidin). Counterstaining was with Harris hematoxylin; the slides were dehydrated and mounted in synthetic resin. Human pituitary was used as positive control. Intracellular PRL positivity was based on presence of at least $1 \%$ of cells with clearly marked cytoplasm $[13,46]$.

\section{Quantitative real-time PCR}

CNS tumor fragments were obtained immediately after surgery, snap-frozen in liquid nitrogen and kept in biofreezer at $-80^{\circ} \mathrm{C}$ until RNA extraction. The procedure for RNA extraction was performed using TriReagent (Ludwig Biotec, Porto Alegre, RS), according to the manufacturer's instructions. RNA was reversely transcribed in a final volume of $21 \mu \mathrm{L}$ using Superscript $1 S T$ Strand System for RT-PCR (Invitrogen, San Diego, CA), according to the manufacturer's instructions. All cDNA samples were quantified using the Nanodrop 1000, measuring absorbance at $260 \mathrm{~nm}$ and $280 \mathrm{~nm}$. Complementary DNAs were of good quality when the $260 / 280$ ratio was greater than 1.7 . The same procedures were adopted for the pool of normal peritumoral tissue as well as the prolactinoma used as positive control.

In order to perform quantitative real-time PCR, all cDNA samples were diluted to a final concentration of $400 \mathrm{ng} / \mu \mathrm{L}$ and amplified using TaqMan gene expression Assay (PRL Hs01062137_m1; GAPDH Hs99999905_m1) and TaqMan Gene Expression Master Mix (4369510) (Applied Biosystems, Foster City, CA) in a total reaction volume of $15 \mu \mathrm{L}$, under the following conditions: initial denaturation at $50^{\circ} \mathrm{C}$ for 2 minutes and at $95^{\circ} \mathrm{C}$ for 10 minutes, followed by 40 cycles at $95^{\circ} \mathrm{C}$ for 15 seconds and $60^{\circ} \mathrm{C}$ for 1 minute. The equipment used was the StepOnePlus (Applied Biosystems, Foster City, CA). For relative quantification the $2^{-\Delta \Delta C T}$ method described by Livak and Schmittgen [47] was adopted. The GAPDH gene was used as reference.A pool consisting of 9 samples of normal peritumoral tissue (gray and white matter CNS and meningothelial tissue) was used as calibrator to allow comparison between CNS tumoral and normal samples. A sample of prolactinoma was used as positive control and mixed reagents without the presence of cDNA were used as negative control. The tests with
CNS tumor samples were performed in duplicate, and the GAPDH gene and PRL gene were always tested in the same assay, avoiding possible differences between assays. The GAPDH gene was detected in all samples. The PRL gene was detected in the prolactinoma sample (positive control) in all assays. In each reaction plate and for each gene tested, the pool of normal CNS tissue samples (calibrator) was performed in triplicate, the positive control (prolactinoma) and negative control in duplicate.

\section{Statistical analyses}

Age-related aspects were first described by mean and standard deviation and comparison between the IH groups (positive and negative) using Student's $t$ test. Next, age was dichotomized into two groups: over and under 40 years old. Statistical analysis was performed with histological meningioma subtypes, astrocytoma and glioblastoma, grouped in other histological oligoastrocytoma subtypes, anaplastic oligodendroglioma, anaplastic ependymomas and unclassified glioma. Among the positive and negative IH groups, categorical data was described by counts and percentages and comparisons made using the Chi-square test or Fisher's exact test in the presence of expected values below 5. The level of significance was $5 \%$ and the data were analyzed by SPSS 17.0.

\section{Abbreviations}

CNS: Central nervous system; IH: Immunohistochemistry; PRL: Prolactin; PRL-R: PRL receptor.

\section{Competing interests}

The authors declared that they have no competing interest.

\section{Authors' contributions}

MGA Conception, Planning, Technical execution, Interpretation of results, Drafting of the article. PLJFS Conception, Planning, Technical assistance, Interpretation of results, Review and approval of the final version. KMB Planning, Technical assistance, Interpretation of results, Review of article.TG Responsible for samples, Technical execution. DDM Responsible for samples, Technical execution. HNP Neurosurgeon, Obtaining of samples. OMC

Conception, Planning, Interpretation of results, Review of article. All authors read and approved the final manuscript.

\section{Acknowledgments}

We would like to thank Rosalva Meurer, Grasiela Agnes, Terezinha Stein and Keli Reiter for their excellent technical assistance.

\section{Author details}

${ }^{1}$ Postgraduate Program in Pathology, Universidade Federal de Ciências da Saúde de Porto Alegre (UFCSPA), Porto Alegre, Brazil. ${ }^{2}$ Center of Neuroendocrinology, Complexo Hospitalar Santa Casa, Porto Alegre/RS, CEP 90020-090, Brazil. 'Biomedicine Student, UFCSPA, Porto Alegre, Brazil.

Received: 19 March 2012 Accepted: 3 January 2013

Published: 14 January 2013

\section{References}

1. Ben-Jonathan $N$, LaPensee CR, LaPensee EW: What can we learn from rodents about prolactin in humans? Endocr Rev 2008, 29:1-31.

2. Ben-Jonathan N, Mershon J, Allen D, Steinmetz R: Extrapituitary prolactin: distribuition, regulation, functions and clinical aspects. Endocr Rev 1996, 17:639-669. 
3. Jabbour HN, Gubbay O, Chritchley H: Prolactin action and signalling in the human endometrium. Reprod Med Rev 2002, 10:117-132.

4. Freeman ME, Kanycska B, Lerant A, Nagy A: Prolactin: structure, function and regulation of secretion. Physiol Rev 2000, 80:1523-1631.

5. Ginsburg E, Vonderhaar BK: Prolactin synthesis and secretion by human breast cancer cells. Cancer Res 1995, 55:2591-2595.

6. Vomachka AJ, Pratt SL, Lockefeer JA, Horseman ND: Prolactin genedisruption arrests mammary gland development and retards T-antigeninduced tumor growth. Oncogene 2000, 19:1077-1084.

7. LaPensee EW, Ben-Jonathan N: Novel roles of prolactin and estrogens in breast cancer: resistance to chemotherapy. Endocr Relat Cancer 2010, 17:91-107.

8. Wennbo H, Kindblom J, Isaksson OG, Tornell J: Transgenic mice overexpressing the prolactin gene develop dramatic enlargement of the prostate gland. Endocrinology 1997, 138:4410-4415.

9. Ahonen TJ, Harkonen PL, Laine J, Rui H, Martikainen PM, Nevalainen MT: Prolactin is a survival factor for androgen-deprived rat dorsal and lateral prostate epithelium in organ culture. Endocrinology 1999, 140:5412-5421.

10. Li H, Ahonen TJ, Alanen K, Xie J, LeBaron MJ, Pretlow TG, Ealley EL, Zhang Y, Nurmi M, Singh B, Martikainen PM, Nevalainen MT: Activation of signal transducer and activator of transcription 5 in human prostate cancer is associated with high histological grade. Cancer Res 2004, 64:4774-4782.

11. Bhatavdekar J, Patel D, Ghosh N, Vora H, Shah N, Karelia N, Balar D, Chikhlikar P, Dave R: Interrelationship of prolactin and its receptor in carcinoma of the colon and rectum:a preliminary report. J Surg Oncol 1994, 55:246-249.

12. Ciccarelli E, Razzore P, Gaia D, Todaro C, Longo A, Forni M, Ghè C, Camann F, Muccioli G, Faccani G, Lanote MM: Hyperprolactinaemia and prolactin binding in benign intracranial tumors. J Neurosurg 2001, 45:70-74

13. Leães CGS, Pereira-Filho A, Pereira-Lima JFS, Dallago CM, Batista RL, Coutinho LMB, Ferreira NP, Oliveira MC: Hyperprolactinemia and immunohistochemical expression of intracellular prolactin and prolactin receptor in primary central nervous system tumors and their relationship with cellular replication. Brain Tumor Pathol 2007, 24:41-46.

14. Abech DMD, Pereira-Lima JFS, Leães CGS, Meurer RT, Barbosa-Coutinho LM, Ferreira NP, Oliveira MC: Cell replication and angiogenesis in central nervous system tumors and their relationship with the expression of tissue prolactin and hyperprolactinemia. OJPathology 2012, 2:50-57.

15. Flowers A: Brain tumors in the older person. Cancer Control 2000, 7:523-538.

16. DeAngelis LM: Brain tumors. N Engl J Med 2001, 344:114-123.

17. Sagar SM, Israel MA: Primary and metastatic tumors of the nervous system. In Harrison's Principle of Internal Medicine. 16th edition. Edited by Jameson JL. New York: McGraw-Hill; 2005:2452.

18. Girolami UD, Anthony DC, Frosch MP: The central nervous system. In Pathologic Basis of Disease. 7th edition. Edited by Cotran R, Kumor V, Robbins S. Philadelphia: WB Saunders; 2004:1243-1357.

19. McCowen K, Glickman J, Black P, Zervas N, Lidov H, Garber J: Gangliocitoma masquerading as a prolactinoma. Case report. J Neurosurg 1999, 91:490-495.

20. Scott IS, Morris LS, Rushbrook SM, Bird K, Vowler SL, Burnet NG, Coleman N: Immunohistochemical estimation of cell cycle entry and phase distribution in astrocytomas: applications in diagnostic neuropathology. Neuropathol Appl Neurobiol 2005, 31:455-466.

21. Ducret T, Boudina S, Sorin B, Vacher AM, Gourdou I, Liguoro D, Guerin J, Bresson-Bepoldin L, Vacher P: Effects of prolactin on intracellular and cell proliferation in human glioma cells. Glia 2002, 38:200-214

22. Jimenez-Hakim E, El-Azouzi M, Black P: The effect of prolactin and bombesin on the growth of meningioma-derived cells in monolayer culture. J Neurooncol 1993, 16:185-190.

23. Fields K, Kulig E, Lloyd RV: Detection of prolactin messenger RNA in mammary and other normal and neoplasic tissues by polymerase chain reaction. Lab Invest 1993, 68:354-360.

24. Schachter BS, Durgerian S, Harlan RE, Pfaff DW, Shivers BD: Prolactin mRNA exists in rat hypothalamus. Endocrinology 1984, 114:1947-1949.

25. Emanuele NV, Jurgens JK, Halloran MM, Tentler JJ, Lawrence AM, Kelley MR: The rat prolactin gene is expressed in brain tissue: detection of normal and alternatively spliced prolactin messenger RNA. Mol Endocrinol 1992, 6:35-42.

26. Kubista M, Andrade JM, Bengtsson M, Forootan A, Jonák J, Lind K, Sindelka R, Sjöback R, Sjögreen B, Strömbom L, Stahlberg A, Zoric N: The real-time polymerase chain reaction. Mol Aspects Med 2006, 27:95-125.

27. Ding C, Cantor CR: Quantitative analysis of nucleic acids - the last Few years of progress. J Biochem Mol Biol 2004, 37:1-10.
28. Bustin AS: Absolute quantification of mRNA using real-time reverse transcription polymerase chain reaction assays. J Mol Endocrinol 2000, 25:169-193.

29. Whitman DF, Dunbar SA: Real-time polymerase chain reaction detection methods. Recent Pat DNA Gene Seq 2008, 2:20-26.

30. Ramos-Vara JA: Technical aspects of immunohistochemistry. Vet Pathol 2005, 42:405-426.

31. van Maanen C, Wouda W, Schares G, von Blumröder D, Conraths FJ, Norton R, Williams DJ, Esteban-Redondo I, Innes EA, Mattsson JG, Björkman C, Fernández-García A, Ortega-Mora LM, Müller N, Sager H, Hemphill A: An interlaboratory comparison of immunohistochemistry and PCR methods for detection of neospora caninum in bovine foetal tissues. Vet Parasitol 2004, 126:351-364.

32. Pisarek H, Stępień T, Kubiak R, Borkowska E, Pawlikowski M: Expression of Somatostatin receptor subtypes in human thyroid tumors: the immunohistochemical and molecular biology (RT-PCR) investigation. Thyroid Res 2009, 2:1-8.

33. Wildemberg LE, Vieira Neto L, Costa DF, Nasciutti LE, Takiya CM, Alves LM, Gadelha MR: Validation of immunohistochemistry for Somatostatin receptor subtype $2 \mathrm{~A}$ in human somatotropinomas: comparison between quantitative real time RT-PCR and immunohistochemistry. J Endocrinol Invest 2011, 34:573-580.

34. Mackay IM: Real-time PCR in the microbiology laboratory. Clin Microbiol Infec 2004, 10:190-212.

35. Wong ML, Medrano JF: Real-time PCR for mRNA quantification. Biotechniques 2005, 39:75-85.

36. Mortarino M, Franceschi A, Mancianti F, Bazzocchi C, Genchi C, Bandi C: Quantitative PCR in the diagnosis of leishmania. Parassitologia 2004, 46:163-167.

37. Llovera M, Pichard C, Bernichtein S, Jeay S, Touraine P, Kelly PA, Goffin V: Human prolactin (hPRL) antagonists inhibit hPRL-activated signaling pathways involved in breast cancer cell proliferation. Oncogene 2000, 19:4695-4705

38. Schaber JD, Fang H, Xu J, Grimley PM, Rui H: Prolactin activates Stat1 but does not antagonize Stat1 activation and growth inhibition by type I interferons in human breast cancer cells. Cancer Res 1998, 58:1914-1919.

39. Das R, Vonderhaar BK: Involvement of SHC, GRB2, SOS and RAS in prolactin signal transduction in mammary epithelial cells. Oncogene 1996, 13:1139-1145.

40. Acosta JJ, Muñoz RM, González L, Subtil-Rodríguez A, Dominguez-Caceres MA, García-Martínez JM, Calcabrini A, Lazaro-Trueba I, Martín-Pérez J: Src mediates prolactin-dependent proliferation of T47DandMCF7 cells via the activation of focal adhesion kinase/Erk1/2 and phosphatidylinositol 3-kinase pathways. Mol Endocrinol 2003, 17:2268-2282.

41. Clevenger CV, Furth PA, Hankinson SE, Schuler LA: The role of prolactin in mammary carcinoma. Endocr Rev 2003, 24:1-27.

42. Aksamitiene E, Achanta S, Kolch W, Kholodenko BN, Hoek JB, Kiyatkin A: Prolactin-stimulated activation of ERK1/2 mitogen-activated protein kinases is controlled by PI3-kinase/Rac/PAK signaling pathway in breast cancer cells. Cell Signal 2011, 23:1794-1805.

43. Fresno Vara JA, Caceres MA, Silva A, Martin-Perez J: Src family kinases are required for prolactin induction of cell proliferation. Mol Biol Cell 2001, 12:2171-2183.

44. Walsh RJ, Slaby FJ, Posner Bl: A receptor-mediated mechanism for the transport of prolactin from blood to cerebrospinal fluid. Endocrinology 1987, 120:1846-1850.

45. Mangurian LP, Walsh RJ, Posner BI: Prolactin enhancement of its own uptake at the choroid plexus. Endocrinology 1992, 131:698-702.

46. Pawlikowski M, Kunert-Radek J, Radek M: Plurihormonality of pituitary adenomas in light of immunohistochemical studies. Endokrynol Pol 2010, 61:63-66.

47. Livak KJ, Schmittgen TD: Analysis of relative gene expression data using real-time quantitative $P C R$ and the $2(-$ delta delta $C(T)$ ) method. Methods 2001, 25:402-408.

doi:10.1186/1477-5751-12-4

Cite this article as: Mendes et al:: Prolactin gene expression in primary central nervous system tumors. Journal of Negative Results in BioMedicine 2013 12:4. 